\title{
The enrichment club
}

\author{
Crystal H. Johnson ${ }^{1}$ \& Kristina Carter ${ }^{1}$
}

Enrichment-through visual, tactile, auditory or edible items-provides animals with psychological stimulation and allows them to exhibit species-typical behavior. This leads to better welfare, and ultimately to better science. Regulatory requirements provide instructions on enrichment specifically for nonhuman primates, but we believe all animals can benefit from enrichment if it is structured for that species. Hired as the Director of Behavior Management and Environmental Enrichment at the Icahn School of Medicine at Mount Sinai, I was tasked with the responsibility of revamping the program to improve enrichment and animal welfare.

With the help of Kristina, our Environmental Enrichment Coordinator, we began to implement an enrichment program that covered the spectrum of animals; from mice to monkeys. While developing the program, we ran into several roadblocks. First, many individuals were not familiar with enrichment and its benefits to animals. Another major issue was manpower; the enrichment team consisted only of me and Kristina. With the new recommended guidelines for social housing, improving the enrichment program, while managing our other daily tasks, was too daunting for only two people.

For some extra help, and also to improve staff familiarity with enrichment, the husbandry staff was enlisted to help implement the program. We quickly realized this was not a sustainable approach as the husbandry staff has to ensure that daily housing and food are adequate for all animals. Putting additional tasks on their plates is sometimes overwhelming, and quite frankly, annoying.

It was from these challenges that the idea for an 'enrichment club' began to take shape.

\footnotetext{
${ }^{1}$ Icahn School of Medicine at Mount Sinai, New York, NY. Correspondence should be addressed to C.H.J (crystal.johnson@mssm.edu)
}

Rather than simply add more responsibilities to people's plates, the enrichment club would provide an opportunity to educate and train staff on environmental enrichment and behavior management, with the long-term mission of attracting staff to engage more with our broader enrichment program. Regardless of what types of animals a staff member is responsible for-most staff work with rodents, where enrichment is not as concentrated-the enrichment club would enable him/her to learn about enrichment and discuss new enrichment ideas. Most importantly, the enrichment club would provide a means for all staff to be directly involved in the enrichment of all the animals under care at our institution, through handson workshops and exercises.

\section{Through our club, enrichment becomes a two-way street.}

During one of our first meetings, we talked about enrichment and its purpose and then discussed a clinical case that was treated using environmental enrichment. The case involved a monkey with alopecia and circling behavior. After behavioral observations, we discovered this monkey was stressed due to a new group of younger female monkeys housed in the same room, as well as her separation from a male monkey that had previously been her neighbor. With relocation of the animal to another room and reuniting her with the male neighbor, the circling and alopecia were both eliminated. Sharing this case with the enrichment club members proved beneficial as they were able to understand enrichment through a real example.

Although the primary purpose of the enrichment club is to increase the welfare of our animals, what about our staff and their welfare? In the old days of biomedical research, personnel were not encouraged to express their feelings or form relationships with animals, and were constantly reminded that the animals were there as research subjects and not as pets. As animal welfare has become a top priority for research institutes, this view has obviously changed, and with the enrichment club, our staff can express themselves and personally give back to the animals that give their lives to the development of new medical therapeutics. Through our club, enrichment becomes a two-way street.

Although the enrichment club has hosted just a few meetings, the benefits are already apparent for both the animals and employees. The ability of our staff to develop relationships with the animals adds value to our mission within the biomedical research community. As we usually shy away from discussing our profession with others due to the fear of ridicule from animal rights activists, the enrichment club brings a sense of pride to our staff that they most definitely deserve. It also emphasizes that the enrichment program is everyone's program, not just the enrichment team's. It gives husbandry a sense of involvement within the overall operation of the program, helps us make our research animals happy, and contributes to the professional development of our entire staff.

With the increased awareness of compassion fatigue, it is critical to develop more projects like enrichment clubs that allow individuals to express their creativity and provide joy and stimulation to our animals. Our long-term goal is to expand the club to other programs within our geographical area, and allow enrichment coordinators, researchers and husbandry staff the opportunity to network and discuss new ideas that benefit animals and their human caretakers. We hope our club can serve as a template for others that want to make enrichment a core component of their program. 